\title{
Experimental Study on Seepage Properties of Postpeak Fractured Rocks under Cyclic Loading-Unloading Confining Stress and Axial Stress
}

\author{
Xiaobo Zhang $\mathbb{D}^{1,2}$ Zuhao Xia, ${ }^{1,2}$ Chi Yao $\mathbb{D}^{1,2}$ Jianhua Yang, $^{1,2}$ and Mingdong Yang ${ }^{3}$ \\ ${ }^{1}$ School of Civil Engineering and Architecture, Nanchang University, Nanchang 330031, China \\ ${ }^{2}$ Key Laboratory of Tailings Reservoir Engineering Safety of Jiangxi Province, Nanchang University, Nanchang 330031, China \\ ${ }^{3}$ Nanjing Anjite Mining and Engineering Co., Ltd., Nanjing 211100, China \\ Correspondence should be addressed to Chi Yao; chi.yao@ncu.edu.cn
}

Received 17 November 2020; Revised 1 December 2020; Accepted 13 December 2020; Published 2 January 2021

Academic Editor: Feng Xiong

Copyright (c) 2021 Xiaobo Zhang et al. This is an open access article distributed under the Creative Commons Attribution License, which permits unrestricted use, distribution, and reproduction in any medium, provided the original work is properly cited.

\begin{abstract}
Excavation in rock masses always encounters safety problems from rock fracture seepage in water-rich areas, which needs to be paid much attention, especially for fractured rocks under complicated stress state. For this reason, the permeability of fractured sandstone and granite is experimentally investigated under cyclic loading-unloading confining stress and axial stress. The variation of permeability coefficient and seepage flow with increasing and decreasing the confining stress and axial stress are comprehensively analyzed. Results show that the changing patterns of permeability with loading-unloading cycles of confining stress for both fractured sandstone and granite are similar. The permeability is most sensitive to the initial loading-unloading stages. After several loading-unloading cycles, the confining stress has little effect on permeability. The seepage flow decreases as the confining stress is unloaded to the same level in the loading process, indicating a hysteresis effect on the recovery of seepage capacity. The seepage properties under cyclic loading-unloading the axial stress are quite different from those under the confining stress. The permeability of fractured sandstone is most sensitive to the first cycle of loading-unloading of axial stress. The irrecoverable shear slide between fractures under the axial stress causes dilatancy or contraction, which makes the permeability coefficient to consecutively decrease at the subsequent cycles. The permeability of granite first decreases during the first loading of axial stress, while this trend is disordered at the subsequent stages no matter loading or unloading the axial stress. This is because of the accumulation of breakage fragments between fractures, which further disturbs the seepage flow. These findings may be useful for further understanding the seepage properties of fractured granite and sandstone under complex loading-unloading history.
\end{abstract}

\section{Introduction}

In the underground rock engineering, the continuous excavating inevitably breaks the original mechanical equilibrium state of rock masses, and the stress redistribution occurs in the surrounding rocks adjacent to the excavation $[1,2]$. During excavation, the underground rock mass is often in a complex stress state that one direction is under loading while other directions may be under unloading $[3,4]$. However, in order to maintain a self-equilibrium state, the stress field may be redistributed repeatedly in the rock masses under cyclic loading and unloading [5-9]. This usually results in the initiation, propa- gation, and coalescence of fractures within rocks subjected to postpeak failure. These fractures act as main seepage channels and significantly influence the permeability of the rock mass in water-rich regions $[10,11]$. The seepage property of rock masses under loading and unloading stress conditions is significantly different from that under a simple loading state. Since fractures inside rock masses play a great role in seepage behavior, the change of seepage properties of fractured rock under a complex stress state is the key factor affecting rock engineering safety $[12,13]$. Therefore, it is of practical significance to consider the effects of cyclic loading and unloading on the seepage properties of fractured rocks. 
Considering different rock types and different stress paths, several researchers have studied the seepage properties of fractured rocks. Wang and Park analyzed the permeability of sedimentary rocks during the full stress-strain process of the triaxial stress test and found that the permeability was not constant, but varied with the stress and strain states in the rocks [14]. Davy et al. conducted a six-month dynamic permeability study on the macrocracked Callovo-Oxfordian argillaceous rock, aiming at distinguishing the contribution to rock permeability of mechanical loading [15]. Wang et al. studied the evolution of the permeability of three different fractured coal specimens under monotonically increasing pore pressure and monotonically increasing confining stress [16]. Zhang et al. carried out triaxial stress tests on sandstones under different loading and unloading rates of confining stress and analyzed the strength, deformation, and permeability characteristics of the specimens [17]. Yin et al. studied the stress-strain-permeability relationship of Chongqing coal specimens under complex stress paths during mining [18]. Zou et al. studied the effects of effective stress on coal permeability under cyclic loading and unloading axial stress [19]. Zhao et al. carried out cyclic loading and unloading tests on sandstone by thermal fluid-solid coupling test system and studied the effects of loading and unloading rates on permeability, deformation, and mechanics of sandstone [20]. Jiang et al. studied the seepage properties of coal specimens under tiered cyclic loading and unloading axial stresses and investigated the recovery of permeability during the loading and unloading process [21]. Zhang et al. performed seepage tests on broken coal samples (BCS) under cyclic loading and unloading to analyze the influence of BCS parameters on stress sensitivity for permeability [22]. The surfaces of natural rock fractures are generally rough, and many researchers have studied the effects of rough-walled feature on the seepage properties of fractured rocks [2325]. Ni et al. used 3D printing technology to establish a rough fracture model, and its seepage test results show that the Forchheimer coefficient is affected to some extent by roughness and pore size [26]. Javadi et al. studied the effects of shearing on the critical Reynolds number and nonlinear flow of rough-walled rock fractures [27]. Chen et al. focused on the experimental evaluation of the Forchheimer equation coefficient for non-Darcy flow in deformable rough fractures and proposed a new criterion for evaluating the applicability of Darcy's law [28]. The aforementioned studies mainly paid attention to the effects of monotonically loading or unloading stress on the seepage properties of fractured rocks or rocklike materials, while there are few studies that have been reported on the seepage evolution of postpeak fractured rocks subjected to cyclic loading and unloading the confining stress and the axial stress. Generally, only the seepage properties under the monotonic loading or monotonic unloading the axial stress or the confining stress are considered. Therefore, it is essential to consider the influence of cyclic loadingunloading on the seepage properties of fractured rocks.

This study is aimed at experimentally studying the seepage property of cyclic loading and unloading the confining stress and the axial stress on postpeak fractured sandstone and granite. The variations of permeability with confining stress and axial stress in cyclic loading and unloading path are separately analyzed. The mechanism behind the difference in seepage behavior before and after each loading and unloading cycle and the whole stress cycle path is investigated. The results are helpful to understand the effects of cyclic loading and unloading the confining stress and the axial stress on the seepage properties of fractured granites and sandstones.

\section{Test Scheme}

2.1. Specimen Preparation. In order to study the effects of loading and unloading the confining stress or the axial stress on seepage properties of postpeak fractured rocks with different lithologic, tight red sandstone and coarse-grained granite collected from construction sites of a hydraulic tunnel were used in the present study. According to the method recommended by the International Society of Rock Mechanics [29], the rocks were processed as standard rock specimens with a size of $\varphi 50 \mathrm{~mm} \times 100 \mathrm{~mm}$. Figure 1 shows the two groups of prepared specimens.

2.2. Test System. The experiments in this study were carried out in a temperature-stress-seepage multifield coupled rock triaxial test system codeveloped by the Wuhan Institute of Rock and Soil Mechanics of the Chinese Academy of Sciences and Nanchang University. The system consists of an automatic servo-controlled device for confining stress, axial stress, and pore pressure (as shown in Figure 2). The device has a capacity for axial stress of up to $500 \mathrm{MPa}$ and a capacity for confining stress of up to $100 \mathrm{MPa}$. The system uses highprecision axial LVDT (linear variable differential transducers), stress data sensor, special toroidal strain sensor, and high-performance data control device for data acquisition. Data such as axial stress, confining stress, displacement, strain, and pore pressure can be recorded during the test in real-time. The system adopts a special hydraulic pressure press device, and the flow pump can output water pressure up to $100 \mathrm{MPa}$ and flow rate up to $60 \mathrm{ml} / \mathrm{min}$, which meets the requirements of the seepage tests carried herein.

2.3. Test Procedure. In order to study the seepage properties under the cyclic loading and unloading the confining stress on postpeak fractured rocks, according to the ISRM test standards [29], the seepage test procedures of this study are as follows:

(1) Each specimen was tightly encapsulated with a fluorinated rubber sleeve using a hot air blower to prevent the oil in the triaxial cell from permeating into the rocks. The specimen was then placed in the multifield coupled rock triaxial confining cylinder (as shown in Figure 2)

(2) A confining stress of $10 \mathrm{MPa}$ was applied at a rate of $0.05 \mathrm{MPa} / \mathrm{s}$. Then, the axial stress was applied at a rate of $0.1 \mathrm{KN} / \mathrm{s}$ until the specimen was fractured. Two specimens after the test are shown in Figure 3. As can be seen, the sandstone specimen formed a throughout shear fracture accompanied by two 


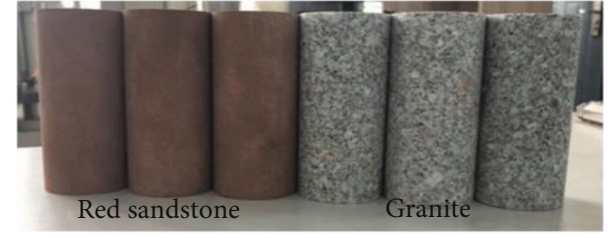

FIGURE 1: Sandstone and granite specimens.

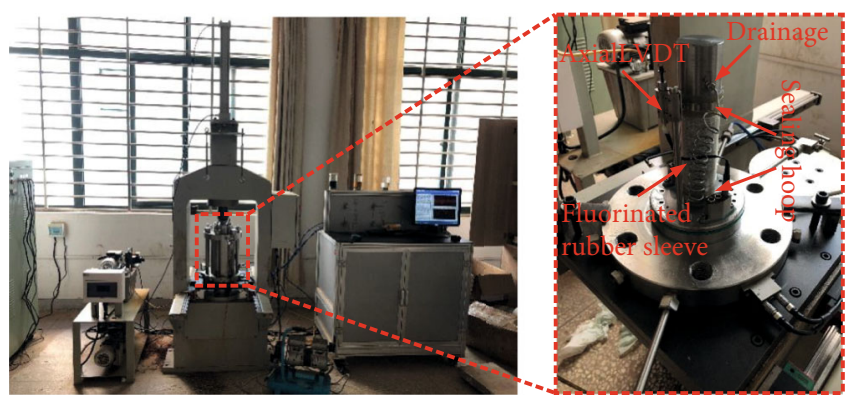

FIgURE 2: Multifield coupled rock triaxial test system of temperature-stress-seepage.

tensile fractures, while the granite specimen formed a single shear fracture connecting the top and bottom end faces. These shear fractures will act as the main seepage channel during the seepage tests

(3) A confining stress of $4 \mathrm{MPa}$ at a rate of $0.05 \mathrm{MPa} / \mathrm{s}$ was applied to the fractured specimen generated in step (2). After the confining stress was stabilized, the water flow was subjected into the inlet of the specimen and the seepage pressure was applied to $3 \mathrm{MPa}$. Once the seepage flow was steady, the seepage flow rate under the confining stress was measured

(4) The confining stress was increased to $6,8,10$, and $12 \mathrm{MPa}$, and the seepage test procedure was repeated as in step (3) at each confining stress. The seepage flow under each confining stress level was measured

(5) After the seepage test under the confining stress of $12 \mathrm{MPa}$ was completed, the confining stress was sequentially unloaded to $10,8,6$, and $4 \mathrm{MPa}$. A seepage test was done following step (3) for each confining stress. Note that the seepage pressure of $3 \mathrm{MPa}$ was maintained at each loading and unloading stage

(6) After completing steps (4) and (5), the first stage of the seepage test was completed. The same procedure was used to carry out all seepage tests for subsequent cycles of loading-unloading of the confining stress

The loading and unloading paths of the confining stress during the seepage test are illustrated in Figure 4. In order to study the influence of cycles of confining stress on the permeability of granite fractures, the cycle number of confining stress of granite specimens was twice more than that of sandstone specimens. The water temperature during the seepage test was approximately kept at $25^{\circ} \mathrm{C}$. The density and kine- matic viscosity of the water at this temperature are $\rho=$ $0.997 \times 10^{3} \mathrm{~kg} / \mathrm{m}^{3}$ and $v=8.999 \times 10^{-7} \mathrm{kPa} / \mathrm{s}$, respectively.

In order to investigate the effect of cyclic of loadingunloading of the axial stress on the permeability of postpeak fractured rocks, seepage tests on fractured sandstone and granite specimens were carried out under cyclic loading-unloading axial stress according to the test procedure of the abovementioned cyclic loading-unloading confining stress. It should be noted that the specimens used in this test were not the same specimens used in previous seepage tests. In this test, the confining stress was maintained at $3 \mathrm{MPa}$, and the seepage pressure was kept steady at $2 \mathrm{MPa}$. The axial stress was loaded and unloaded to $0,1,3,5,7$, and $9 \mathrm{MPa}$ in the seepage test. The specific loading and unloading paths of the axial stress are presented in Figure 5.

During the test, it is assumed that the water flow through the rock fracture conforms to Darcy's law. The permeability coefficient of the specimen can be obtained according to the pressure difference between the two end faces and the seepage flow rates recorded. The permeability coefficient can be calculated with the following formula:

$$
k=\frac{q L \gamma_{w}}{\Delta P A},
$$

where $k$ is the permeability coefficient, $\mathrm{m} / \mathrm{s} ; q$ is the seepage flow through the specimen, $\mathrm{m}^{3} / \mathrm{s} ; L$ is the length along the flow direction, $\mathrm{m} ; \gamma_{w_{2}}$ is the unit weight of the fluid, $\mathrm{N} / \mathrm{m}^{3}$; $A$ is the flow area, $\mathrm{m}^{2} ; \Delta P$ is the seepage pressure difference between both ends of the specimen, $\mathrm{Pa}$.

\section{Seepage Properties under Cyclic Loading- Unloading Confining Stress}

3.1. Permeability Variation with Confining Stress. Known by Eq. (1), the permeability coefficient can reflect the seepage capacity of water flow through the fracture. Figure 6 shows the variation of the permeability coefficient with the confining stress during different loading and unloading processes of fractured sandstone and granite specimens.

From Figure 6, it can be found that the permeability coefficients of sandstone specimens under three cycles and granite specimens under five cycles of loadingunloading confining stress show a similar variation trend with changing the confining stress. In the loading stage of confining stress, the permeability of both sandstone and granite specimens decreases with increasing confining stress. The reason for that result is that increasing the confining stress causes closure of the fractures. The decreased aperture restrained the water seepage and thereby reduced the flow capacity. In the unloading stage of confining stress, the permeability of both sandstone and granite specimens increased. The reason for that result is that the fracture surfaces in the rock reopen. The increased aperture increases the water seepage.

In order to study the evolution of seepage properties of fractured rocks under the influence of cyclic loading and unloading the confining stress, Figure 7 shows the variation of the permeability coefficient under the full-path of 


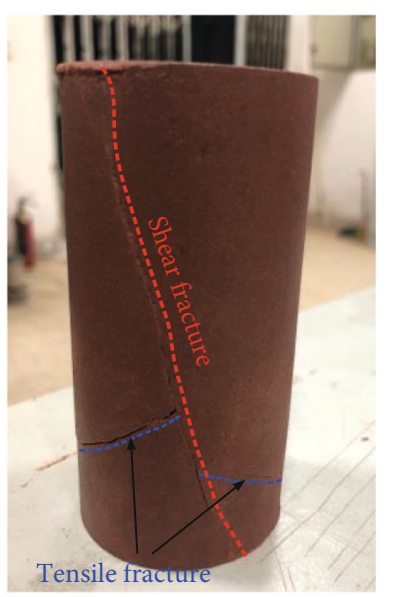

(a)

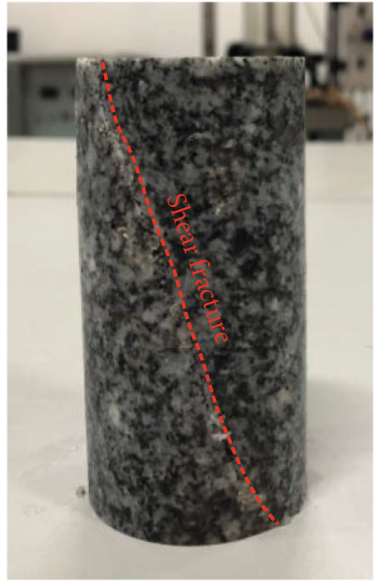

(b)

Figure 3: Fractured (a) sandstone and (b) granite specimens.

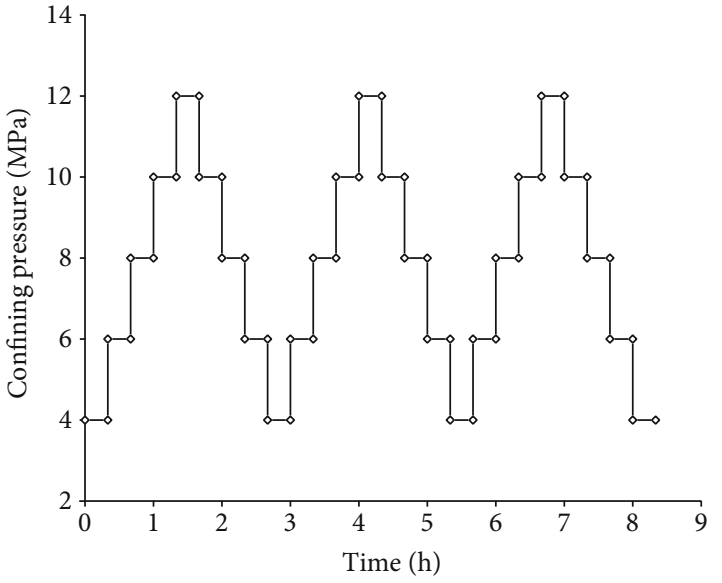

(a)

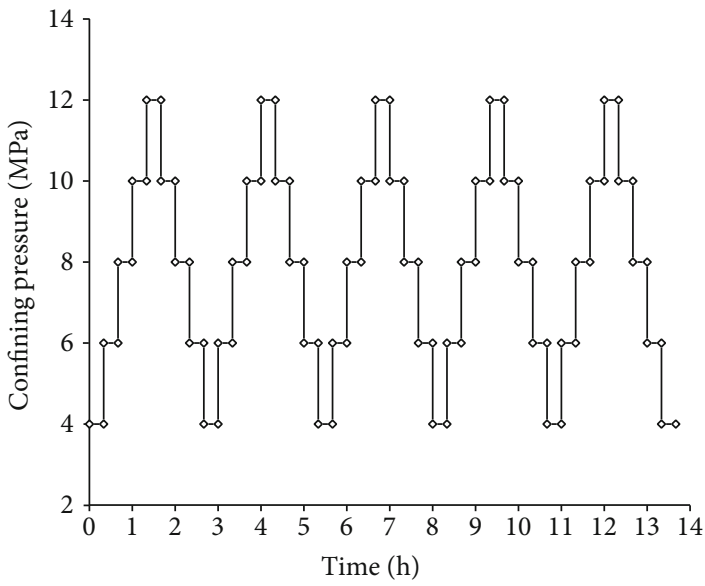

(b)

FIgURE 4: Cyclic loading-unloading path of confining stress for (a) sandstone and (b) granite specimens.

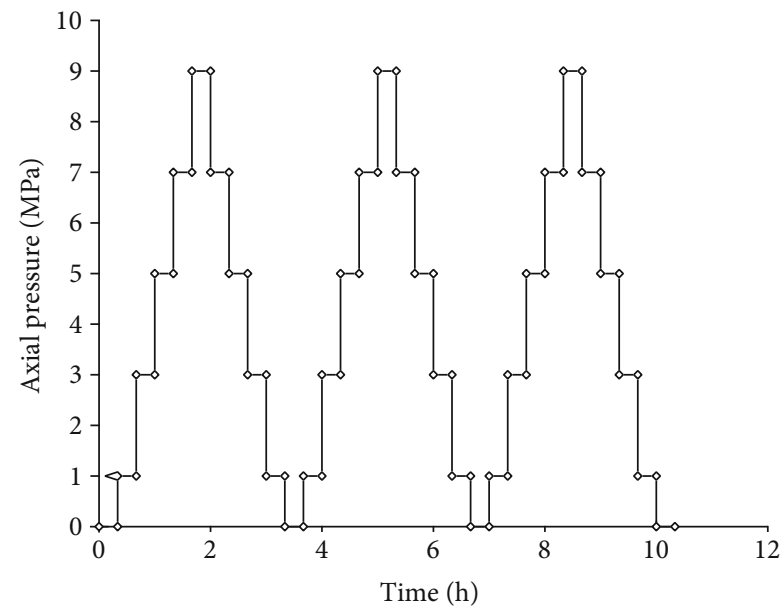

FIGURE 5: Cyclic loading-unloading path of axial stress for both sandstone and granite specimens. loading-unloading the confining stress. As can be seen from Figure 7, the first loading-unloading cycle of confining stress has the greatest influence on the permeability of both fractured sandstone and granite specimens, which indicates that the permeability of fractured sandstone and granite is most sensitive to the initial confining stress history. After several loading-unloading cycles of confining stress, the permeability coefficients of both sandstone and granite specimens are remarkably reduced compared with those of the first cycle. The overall trend in the permeability coefficient is a decrease of magnitude with increasing the cycles of loading-unloading of the confining stress.

By comparing Figures $7(a)$ and $7(b)$, it can be found that although the permeability coefficients of granite are an order of magnitude larger than those of sandstone, the variation of the permeability coefficient with the loading-unloading cycles of confining stress for both sandstone and granite specimens is in the same change pattern. The permeability coefficients approached a constant level 


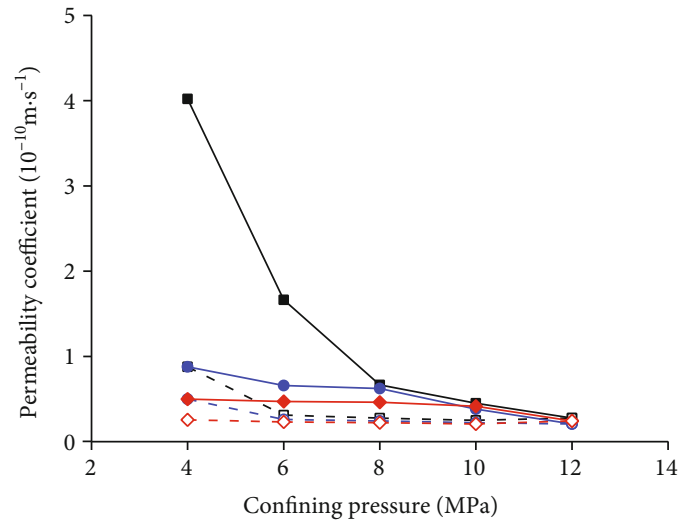

$\rightarrow-1$ st stage loading $\quad-\circ-2$ nd stage unloading

$\rightarrow$ 2nd stage loading $\quad-\diamond-3$ rd stage unloading

(a)

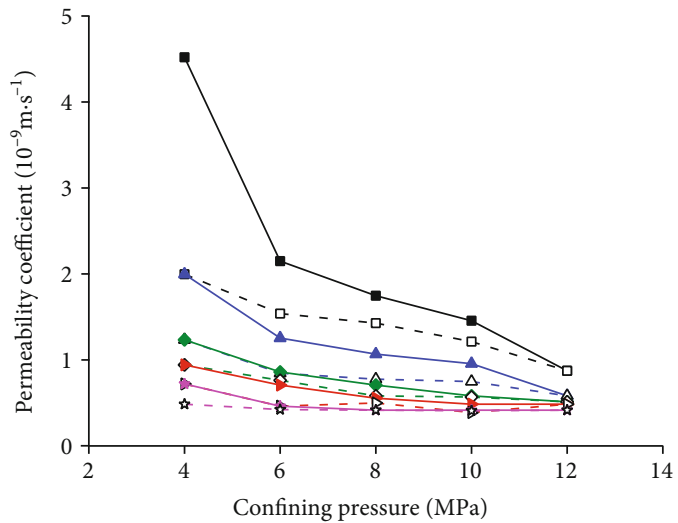

$\rightarrow-1$ st stage loading $\quad-\diamond-3$ rd stage unloading

- $\square-$ 1st stage unloading $\longrightarrow$ 4th stage loading

- 2nd stage loading $\quad \longrightarrow-\quad$ th stage unloading

$-\Delta-2$ 2nd stage unloading $\quad$ — 5 th stage loading

$\multimap$ 3rd stage loading _ $\quad$ - 5 th stage unloading

(b)

Figure 6: Relationship between the permeability coefficient and the confining stress under different loading and unloading cycles for fractured (a) sandstone and (b) granite specimens.

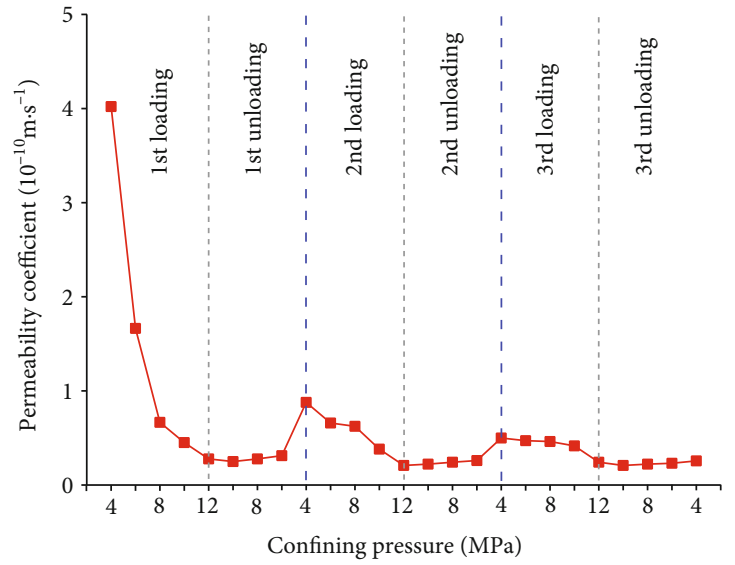

(a)

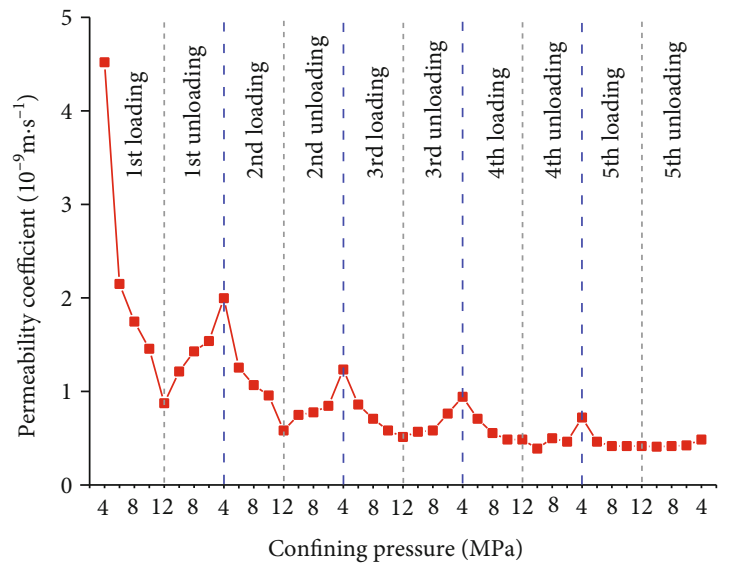

(b)

FIGURE 7: Variation of permeability coefficient under the full-path of loading-unloading the confining stress for fractured (a) sandstone and (b) granite specimens.

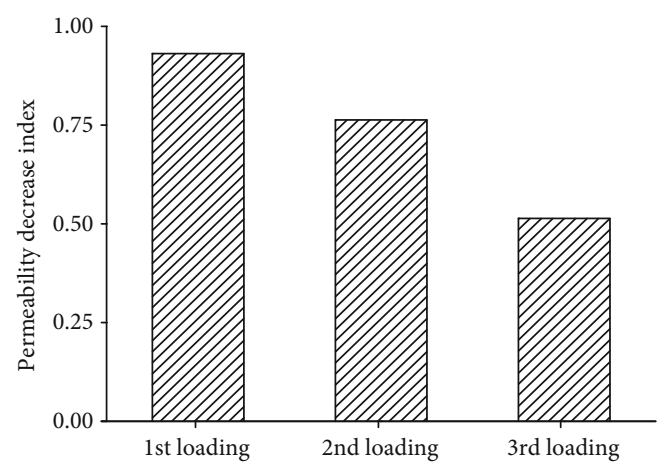

(a)

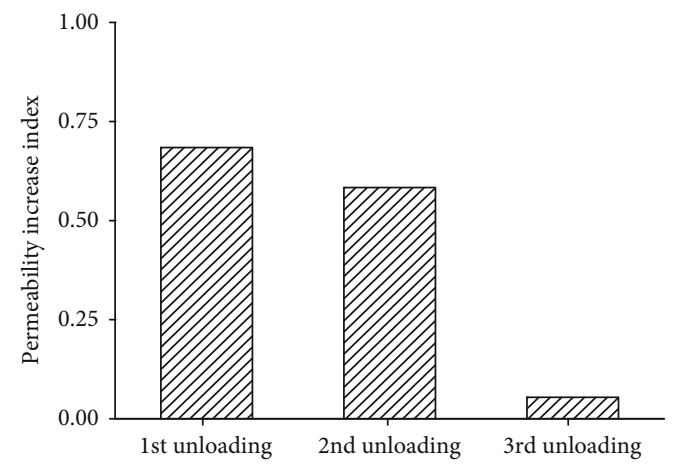

(b)

FIgURE 8: Permeability variation index for fractured sandstone specimens in all cycles of confining stress. 


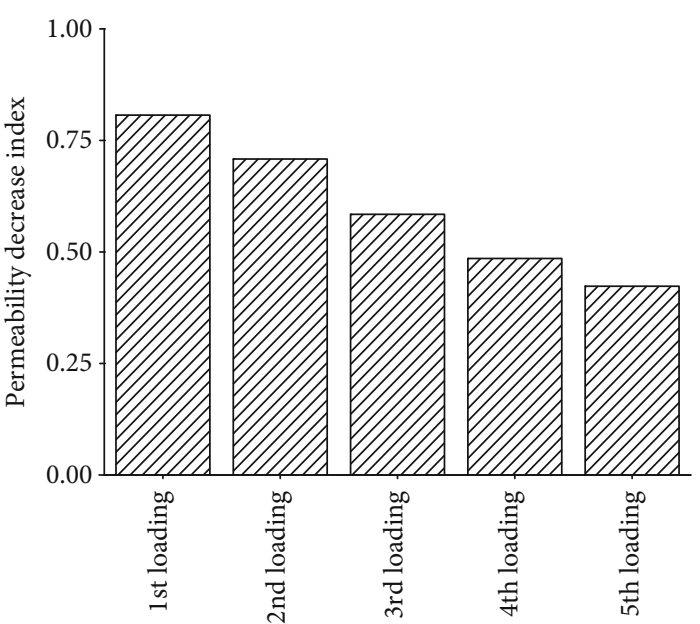

(a)

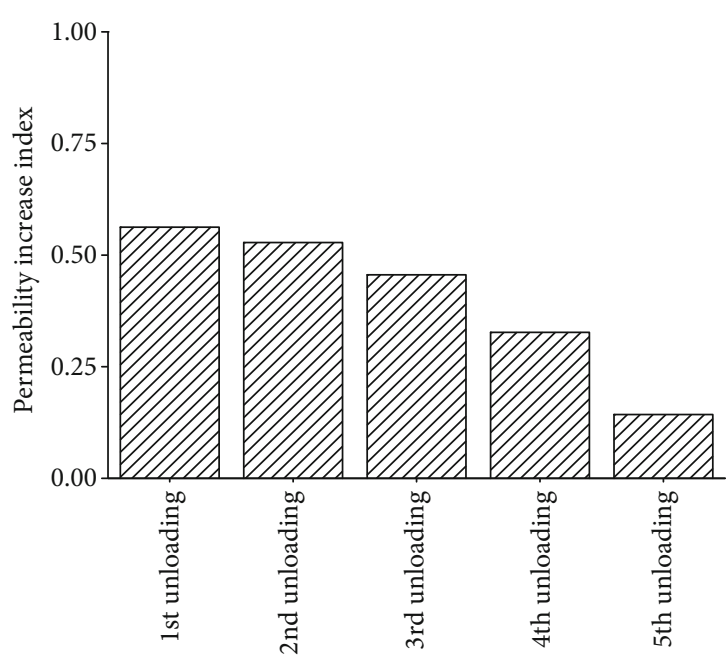

(b)

FIgURE 9: Permeability variation index for fractured granite specimens in all cycles of confining stress.
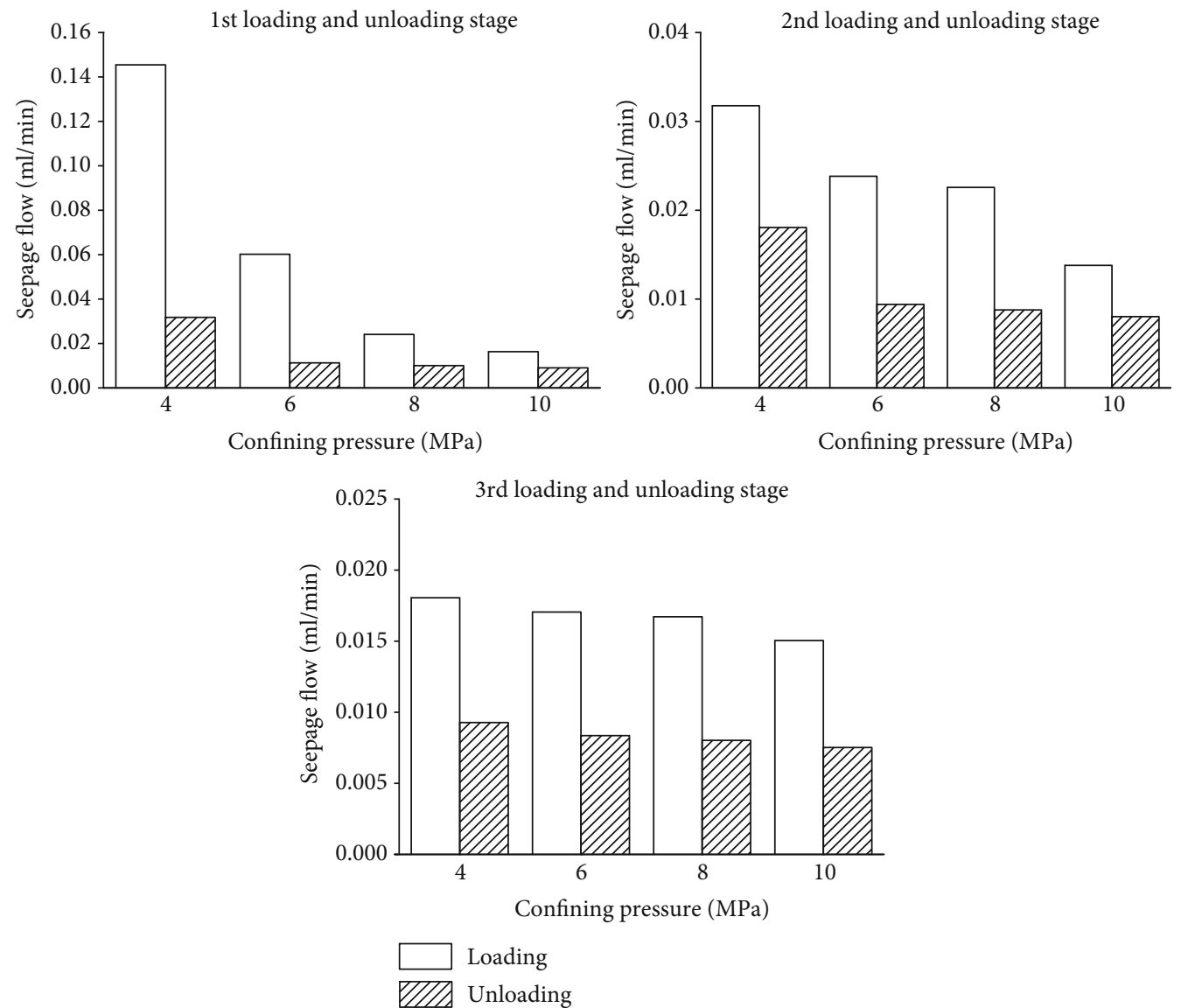

FIGURE 10: Comparison of seepage flow in cyclic loading-unloading confining process of postpeak fractured sandstone.

after three cycles for sandstone specimens and five cycles for granite specimens. After that increasing or decreasing the confining stress has little effect on permeability.

As can be seen in Figure 7, the variation of permeability coefficients is different in different loading-unloading cycles of confining stress for both sandstone and granite specimens. Therefore, to characterize the variation of permeability during different cycles of loading-unloading of the confining stress, two dimensionless indexes are proposed. The permeability variation (increase and decrease) indexes are defined 

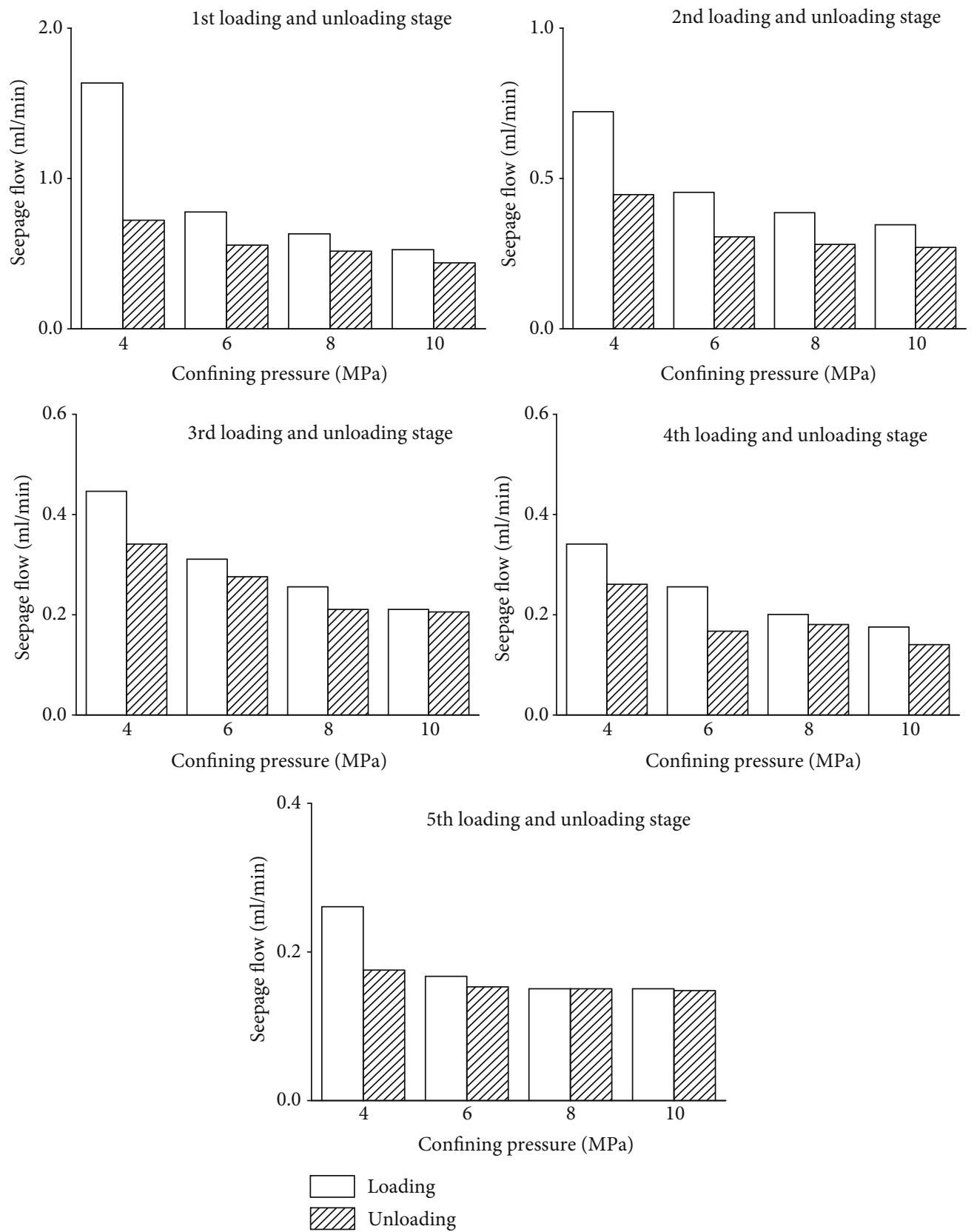

FIGURE 11: Comparison of seepage flow in cyclic loading-unloading confining process of postpeak fractured granite.

by normalizing the difference of the permeability coefficient at the minimum and maximum confining stress by the initial permeability coefficient in every loading or unloading stages of confining stress, which are expressed as:

$$
\begin{gathered}
I_{\mathrm{kl}}=\left(k_{i}-k_{p}\right) / k_{i}, \\
I_{\mathrm{ku}}=\left(k_{s}-k_{p}\right) / k_{p},
\end{gathered}
$$

where $I_{\mathrm{kl}}$ is the permeability decrease index at the loading confining stage; $I_{\mathrm{ku}}$ is the permeability increase index at the unloading confining stage; $k_{i}$ and $k_{p}$ are, respectively, the permeability coefficient at the minimum and maximum con- fining stress at the loading stage; $k_{s}$ is the permeability coefficient at the minimum confining stress at the unloading stage.

Figures 8 and 9 show the permeability variation (increase and decrease) indexes at different loading and unloading confining stress stages for fractured sandstone and granite, respectively. As can be seen, both the permeability increase index at loading stages and the permeability decrease index at unloading stages decrease with the increase of loading and unloading cycles. This further indicates that the permeability variations of fractured specimens are most sensitive to the initial loading-unloading history of confining stress. At the first loading stage of confining stress, the fracture within rock specimens was subjected to compression at the 


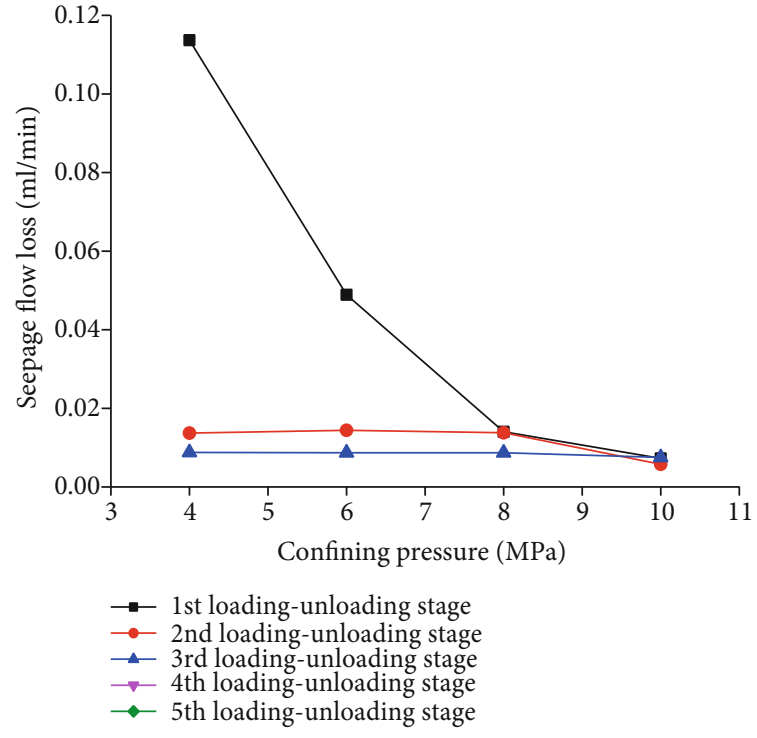

(a)

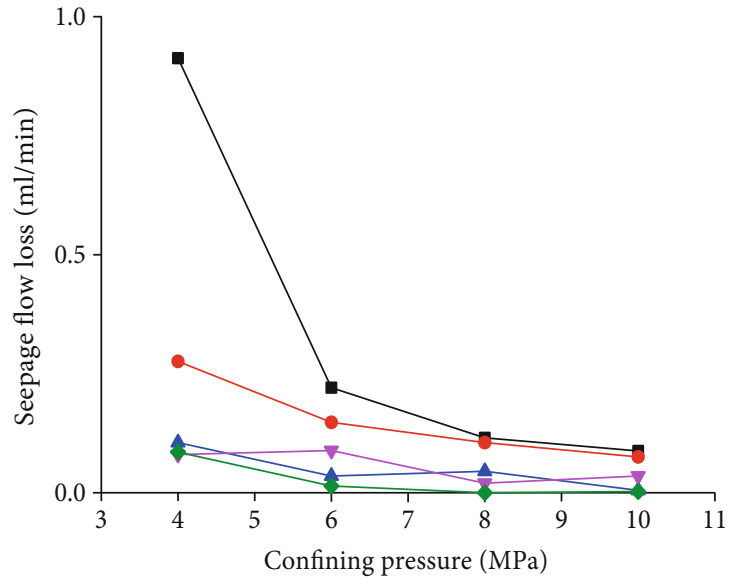

(b)

Figure 12: Curve of seepage flow loss with confining stress for fractured (a) sandstone and (b) granite specimens.

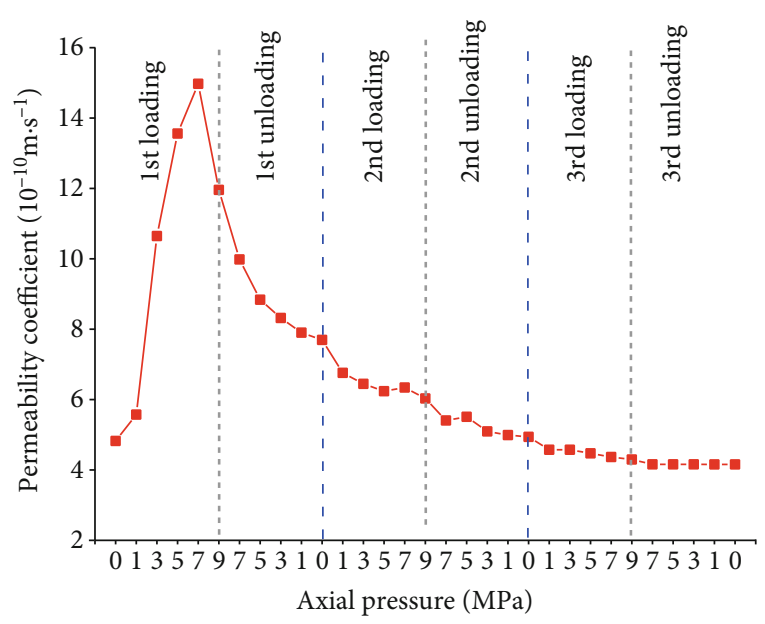

FIGURE 13: Variation of permeability coefficient under the full-path of loading-unloading the axial stress for fractured sandstone.

maximum extent, which significantly restrained the seepage and resulted in the largest permeability decrease index; while at the first unloading stage, the fracture was reopened to at the maximum extent due to the stress release, which enlarged the seepage channel and resulted in the largest permeability increase index. As increasing the loading and unloading times, the amount of deformation within the fractured specimens decreased gradually, and the variation of permeability of the specimen decreases gradually.

3.2. Characteristics of Seepage Flow Loss. From Figures 8 and 9 , the permeability decrease index during each loading cycle is larger than the permeability increase index at the corresponding unloading cycle. This indicates that the closure amount caused by loading was larger than the opening during unloading. The closure and opening of fractures within the specimen significantly influence the flow rate in the seepage channel. The seepage flow lose is important to represent the energy change of the water flow through fractures [30, 31]. Therefore, to further characterize the change of seepage flow loss in postpeak fractured sandstone, Figures 10 and 11 , respectively, show the seepage flow during the loading and unloading of the confining stress for the postpeak fractured sandstone and granite in the same stage. As can be seen from Figures 10 and 11, when the confining stress is unloaded to the same level as the loading process, the seepage flow through the fracture surface of the specimen decreased significantly, which indicates that there is a significant hysteresis effect on the recovery of seepage capacity on the fracture surface. This is because there was a residual closure after a loading process of confining stress that could not be recovered in the subsequent unloading process, which narrowed the seepage channel and thus decreased the flow through rock fractures.

From Figures 10 and 11, it seems that the hysteresis effect on the recovery of seepage capacity was more evident in fractured sandstone. In order to quantify the magnitude and variation of the seepage flow loss under the same confining stress during loading and unloading cycles, the seepage flow loss of the fractured specimens was calculated by the following formula:

$$
\Delta F_{i}=F_{l i}-F_{u i},
$$

where $\Delta F_{i}$ is the seepage flow loss at the $i$-th confining stress level; $F_{l i}$ and $F_{u i}$ are the seepage flow at the $i$-th confining stress during the loading and unloading, respectively.

Figure 12 illustrates the seepage flow loss of postpeak fractured sandstone and granite with cyclic loading and unloading the confining stress. It can be found from Figure 12 that the amount of seepage flow loss showed a decreasing trend as the confining stress increased for each 


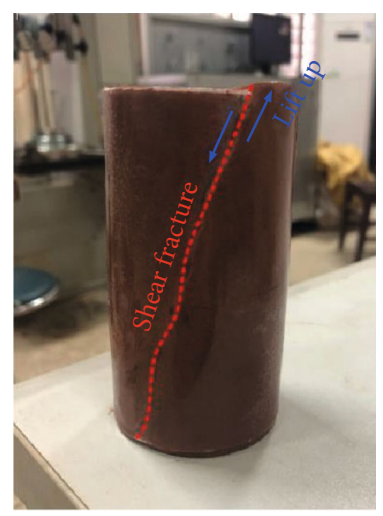

(a)

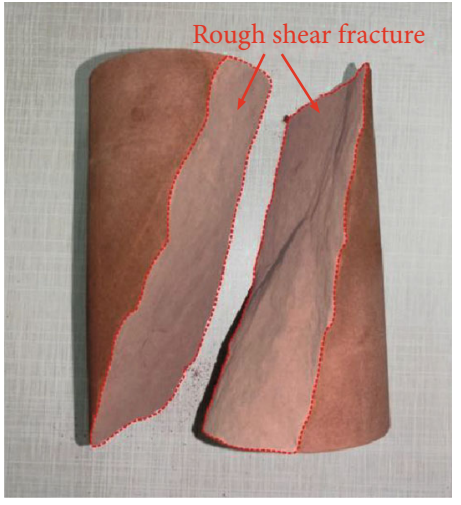

(b)

FIGURE 14: Picture of (a) fractured sandstone after seepage test and (b) rupture characteristics of fractures inside the specimen.

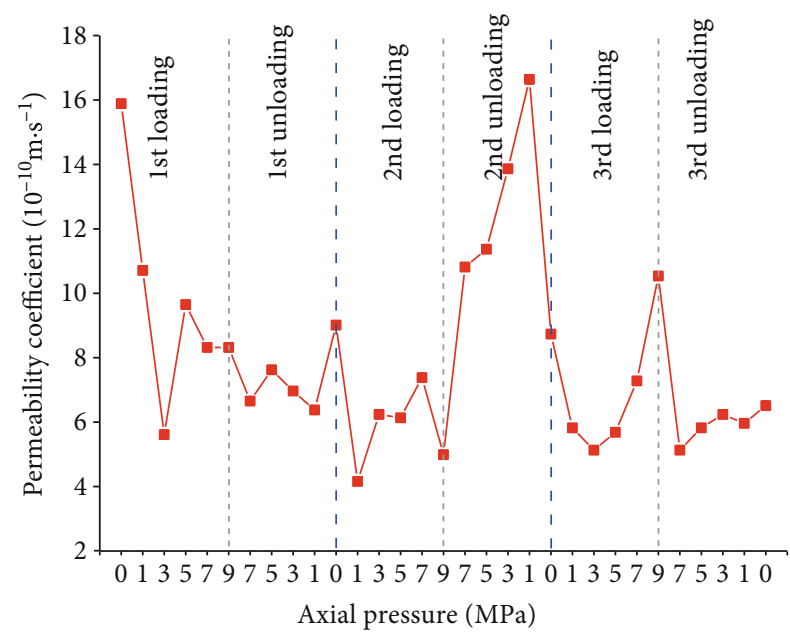

FIGURE 15: Variation of permeability coefficient under the full-path of loading-unloading the axial stress for fractured granite.

loading-unloading stage of confining stress. The effect of confining stress on the amount of seepage flow loss was remarkable at the first stage of cyclic loading-unloading confining stress. For example, under the confining stress of $4 \mathrm{MPa}$, the seepage flow losses by loading-unloading confining stress were $0.113 \mathrm{ml} / \mathrm{min}$ and $0.913 \mathrm{ml} / \mathrm{min}$ for sandstone and granite, respectively; while as the confining stress increased to $10 \mathrm{MPa}$, the seepage flow losses were $0.007 \mathrm{ml} / \mathrm{min}$ and $0.088 \mathrm{ml} / \mathrm{min}$ for sandstone and granite, respectively. At the subsequent cyclic stage of loadingunloading confining stress, however, the amount of seepage flow losses was significantly reduced. For example, the amount of seepage flow loss at the subsequent cyclic stage ranged from 0.006 to $0.014 \mathrm{ml} / \mathrm{min}$ and 0.003 to $0.276 \mathrm{ml} / \mathrm{min}$, receptively, for sandstone and granite. This is because the seepage was not so sensitive to the cyclic of loading-unloading confining stress since the fractures within the specimen yielded irreversible deformation during the initial loading process. In the process of loading and unloading confining stress, the seepage flow loss of the specimen was much smaller than that of the former process.

\section{Seepage Properties under Cyclic Loading- Unloading Axial Stress}

4.1. Permeability Variation for Fractured Sandstone. According to the experimental results, the variation of the permeability coefficient under the full-path of loading-unloading the axial stress of postpeak fractured sandstone is plotted in Figure 13. From Figure 13, it can be found that the permeability coefficient of postpeak fractured sandstone has a peak at the first loading-unloading cycle of axial stress. The permeability coefficient dramatically increases as increasing the axial stress at the first loading stage, reaching its peak of $14.95 \times 10^{-10} \mathrm{~m} \cdot \mathrm{s}^{-1}$ at the $7 \mathrm{MPa}$ axial stress level. At this stage, as the axial stress being loaded to $9 \mathrm{MPa}$, the permeability coefficient sharply decreased to $11.95 \times 10^{-10} \mathrm{~m} \cdot \mathrm{s}^{-1}$. This decreasing trend in permeability coefficient continued at the first unloading stage as the axial stress being unloaded. At the subsequent two stages of cyclic loading-unloading the axial stress, the permeability coefficient showed a continuous downward trend no matter the axial stress is loaded or unloaded. It is clear that the permeability variation of fractured sandstone is most sensitive to the first stage of cyclic loading-unloading axial stress. As the axial stress cycle increases, the permeability variation is not so sensitive to cyclic loading-unloading axial stress, and the permeability coefficient gradually decreases to a stable level of $4.15 \times$ $10^{-10} \mathrm{~m} \cdot \mathrm{s}^{-1}$ finally.

By observing the specimen after the test (Figure 14(a)), it is found that the right half of the sandstone specimen was lifted up along the shear fracture induced by the triaxial compression prior to the seepage test. This is because under the action of axial stress, there is sliding behavior between the two halves of the fractured specimen. Since the axial stress was applied approximately along the fracture, the two halves of the fractured specimen were subjected to shearing. As can be seen in Figure 14(b), the two fracture surfaces of the specimen are rough, which probably caused the dilatancy or contraction in the seepage test under the axial stress. The two halves of the specimen separated with sliding due to the dilatancy, which confirms the tendency of the permeability coefficient to increase rapidly at the first loading stage of axial 


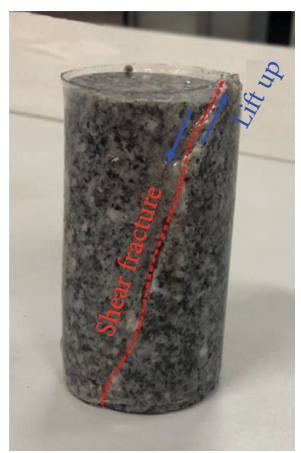

(a)

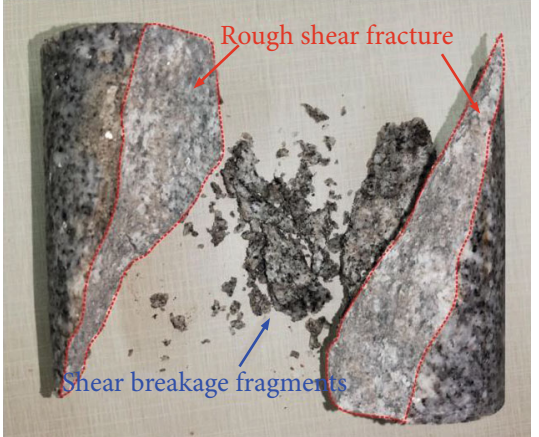

(b)

Figure 16: Picture of (a) fractured granite after seepage test and (b) rupture characteristics of fractures inside the specimen.

stress in Figure 13. The main reason is that the dilatancy increases the aperture of the fracture, thereby improving the seepage capacity and of course increasing the permeability coefficient. The $7 \mathrm{MPa}$ may be a key level of axial stress at the first loading stage, which indicates that the shear dilatancy and shear contraction occur under an axial stress less than $7 \mathrm{MPa}$ and more than $7 \mathrm{MPa}$, respectively. The shear contraction makes the aperture being reduced and results in a smaller permeability coefficient. Because the shear slide between the two halves of the fractured specimen is irrecoverable, at the subsequent stages of cyclic loading-unloading axial stress, the shear slide gradually develops to a residual state that remains a minimum dilatancy or a maximum contraction under the combined action of cyclic loadingunloading axial stress and constant confining stress. Therefore, at the subsequent stages of cyclic loading-unloading axial stress, the permeability coefficient consecutively decreases as shown in Figure 13.

4.2. Permeability Variation for Fractured Granite. The permeability variation for postpeak fractured granite under cyclic loading-unloading axial stress is presented in Figure 15. As can be seen, in contrast to the results of sandstone, the permeability coefficient of granite firstly decreases at the initial loading of axial stress at the first loading stage, while this trend changes to be disordered at the subsequent stages no matter loading or unloading the axial stress.

Debris cumulated between the two halves of fracture due to the continuous shear action. As a result, the permeability variation of the specimen becomes relatively random, and there is great uncertainty in predicting the permeability variation of the fractured granite. Therefore, because of the complex crystalline structure of granites and complicated failure characteristics under triaxial compression, the variation of permeability of fractured granite is more complex, especially under cyclic loading-unloading axial stress.

By observing the specimen after the test (Figure 16(a)), it is found that the right half of the granite specimen was also lifted up along the shear fracture induced by the triaxial compression prior to the seepage test. This is also because under the action of axial stress, there is sliding behavior between the two halves of the fractured specimen. Because the granite used in the test contains coarse grain, which is easy to be sheared off, the fracture within the granite was possibly surfed severe shear rupture and debris could be generated between two fracture surfaces at the initial loading stage. As can be seen in Figure 16(b), there are a number of breakage fragments between the fracture surfaces. The existence of these fragments in granite specimen makes its seepage channel far more complicated than the single seepage channel of sandstone as discussed in Figure 14. The subsequent stages of loading-unloading axial stress generate more debris, and the big debris is possibly broken and is further crushed. Under the constant confining stress, the generated debris blocks the seepage channel, and the constant seepage pressure cannot wash away the accumulated debris. All the effect makes the axial stress no longer the main factor affecting the permeability of the fractured granite under cyclic loadingunloading axial stress. Therefore, the permeability variation of fractured granite herein shows up as no predictable with the cyclic loading-unloading axial stress as shown in Figure 15.

\section{Conclusions}

Postpeak fractured sandstone and granite specimens were generated through triaxial tests, which were then subjected to seepage tests under cyclic loading-unloading the confining stress and axial stress, respectively. The main conclusions are summarized as follows:

(1) The permeability coefficients of sandstone and granite under cyclic loading-unloading confining stress show a similar variation trend with changing the confining stress. Loading the confining stress decreases the permeability coefficient due to the compression closure of fracture surfaces. Unloading the confining stress increases the permeability coefficient because of the reopening of fractures that increases the hydraulic aperture. The first loading-unloading cycle of confining stress has the greatest influence on the permeability. After several loading-unloading cycles of confining stress, the permeability coefficients are remarkably reduced 
(2) There is a significant hysteresis effect on the recovery of seepage capacity of fractures. The residual closure after a loading process of confining stress could not be recovered in the subsequent unloading process, narrowing the seepage channel and thus decreases the flow through rock fractures. The amount of seepage flow loss showed a decreasing trend as the confining stress increases for each loading-unloading stage. The effect of confining stress on the amount of seepage flow loss is remarkable at the first stage of cyclic loading-unloading confining stress; while at the subsequent cyclic stages, this effect is remarkably reduced

(3) The permeability coefficient of fractured sandstone has a peak under the $7 \mathrm{MPa}$ axial stress at the first stage of loading-unloading the axial stress. In this stage, the permeability coefficient firstly increases to the peak and then sharply decreases as increasing the axial stress. At the subsequent stages, the permeability coefficient continuously decreases no matter loading or unloading the axial stress. This is because there is shear sliding behavior between fractures under the action of axial stress. The rough fracture probably causes dilatancy or contraction in the seepage test. At the subsequent stages of cyclic loadingunloading axial stress, the irrecoverable shear slide gradually develops to a residual state, leading to the permeability coefficient consecutively decreases

(4) The permeability coefficient of granite firstly decreases at the initial loading of axial stress, while this trend changes to be disordered at the subsequent stages no matter loading or unloading the axial stress. Since the granite contains coarse grains, breakage fragments are found to cumulate between the two halves of fracture due to the continuous shear action by the axial stress. As a result, the permeability variation becomes relatively random and there is great uncertainty in predicting the permeability variation. The complicated failure characteristics of granite make the permeability of fractured granite to be more complex especially under cyclic loading-unloading axial stress

\section{Data Availability}

The data used to support the findings of this study can be obtained from the corresponding author upon request.

\section{Conflicts of Interest}

The authors declare that they have no conflicts of interest regarding the publication of this paper.

\section{Acknowledgments}

This work is supported by the National Natural Science Foundation of China (U1765207, 51769014, 51969015,
52004127 and 52079062) and the Natural Science Foundation of Jiangxi Province (20202BAB204033).

\section{References}

[1] F. Nicollin, D. Gibert, N. Lesparre, and C. Nussbaum, “Anisotropy of electrical conductivity of the excavation damaged zone in the Mont Terri underground rock laboratory," Geophysical Journal International, vol. 181, no. 1, pp. 303-320, 2010.

[2] J. Yang, J. Cai, C. Yao, P. Li, Q. Jiang, and C. Zhou, "Comparative study of tunnel Blast-Induced vibration on tunnel surfaces and inside surrounding rock," Rock Mechanics and Rock Engineering, vol. 52, no. 11, pp. 4747-4761, 2019.

[3] C. Zhu, M. He, M. Karakus, X. Cui, and Z. Tao, "Investigating toppling failure mechanism of anti-dip layered slope due to excavation by physical modelling," Rock Mechanics and Rock Engineering, vol. 53, no. 11, pp. 5029-5050, 2020.

[4] Z. Chun, T. Zhigang, Y. Sen, and Z. Shuai, "V shaped gully method for controlling rockfall on high-steep slopes in China," Bulletin of Engineering Geology and the Environment, vol. 78, no. 4, pp. 2731-2747, 2019.

[5] H. Munoz and A. Taheri, "Local damage and progressive localisation in porous sandstone during cyclic loading," Rock Mechanics and Rock Engineering, vol. 50, no. 12, pp. 32533259, 2017.

[6] J. H. Yang, C. Yao, Q. H. Jiang, W. B. Lu, and S. H. Jiang, "2D numerical analysis of rock damage induced by dynamic in-situ stress redistribution and blast loading in underground blasting excavation," Tunnelling and Underground Space Technology, vol. 70, pp. 221-232, 2017.

[7] X. Zhang, H. Chen, C. Yao et al., "Seepage characteristics of triaxial compression-induced fractured rocks under varying confining pressures," International Journal of Geomechanics, vol. 20, no. 9, article 04020160, 2020.

[8] X. T. Feng, Y. Gao, X. Zhang, Z. Wang, Y. Zhang, and Q. Han, "Evolution of the mechanical and strength parameters of hard rocks in the true triaxial cyclic loading and unloading tests," International Journal of Rock Mechanics and Mining Sciences, vol. 131, article 104349, 2020.

[9] C. Zhu, X. Xu, W. Liu et al., "Softening damage analysis of gypsum rock with water immersion time based on laboratory experiment," IEEE Access, vol. 7, pp. 125575-125585, 2019.

[10] Z. Ye, Q. Jiang, C. Yao et al., "The parabolic variational inequalities for variably saturated water flow in heterogeneous fracture networks," Geofluids, vol. 2018, Article ID 9062569, 16 pages, 2018.

[11] Z. Li, C. He, Z. Chen, S. Yang, J. Ding, and Y. Pen, "Study of seepage field distribution and its influence on urban tunnels in water-rich regions," Bulletin of Engineering Geology and the Environment, vol. 78, no. 6, pp. 4035-4045, 2019.

[12] C. Yao, J. F. Shao, Q. H. Jiang, and C. B. Zhou, "A new discrete method for modeling hydraulic fracturing in cohesive porous materials," Journal of Petroleum Science and Engineering, vol. 180, no. 9, pp. 257-267, 2019.

[13] C. Zhu, X. Xu, X. Wang et al., "Experimental investigation on nonlinear flow anisotropy behavior in fracture media," Geofluids, vol. 2019, Article ID 5874849, 9 pages, 2019.

[14] J. A. Wang and H. D. Park, "Fluid permeability of sedimentary rocks in a complete stress-strain process," Engineering Geology, vol. 63, no. 3-4, pp. 291-300, 2002. 
[15] C. Davy, F. Skoczylas, J. D. Barnichon, and P. Lebon, "Permeability of macro-cracked argillite under confinement: gas and water testing," Physics and Chemistry of the Earth, Parts $A / B / C$, vol. 32, no. 8-14, pp. 667-680, 2007.

[16] S. Wang, D. Elsworth, and J. Liu, "Permeability evolution in fractured coal: the roles of fracture geometry and water-content," International Journal of Coal Geology, vol. 87, no. 1, pp. 13-25, 2011.

[17] D. Zhang, X. Qi, G. Yin, and B. Zheng, "Coal and rock fissure evolution and distribution characteristics of multi-seam mining," International Journal of Mining Science and Technology, vol. 23, no. 6, pp. 835-840, 2013.

[18] G. Yin, M. Li, J. G. Wang, J. Xu, and W. Li, "Mechanical behavior and permeability evolution of gas infiltrated coals during protective layer mining," International Journal of Rock Mechanics and Mining Sciences, vol. 80, pp. 292-301, 2015.

[19] J. Zou, W. Chen, D. Yang, H. Yu, and J. Yuan, “The impact of effective stress and gas slippage on coal permeability under cyclic loading," Journal of Natural Gas Science and Engineering, vol. 31, pp. 236-248, 2016.

[20] H. Zhao, D. Zhang, C. Liu, B. Deng, G. Bian, and W. Li, "Mechanical characteristics and permeability evolution rule of coal under loading-unloading conditions," Journal of University of Science and Technology Beijing, vol. 38, no. 120, pp. 1674-1680, 2016.

[21] C. Jiang, M. Duan, G. Yin et al., "Experimental study on seepage properties, AE characteristics and energy dissipation of coal under tiered cyclic loading," Engineering Geology, vol. 221, pp. 114-123, 2017.

[22] C. Zhang, S. Tu, and L. Zhang, "Analysis of broken coal permeability evolution under cyclic loading and unloading conditions by the model based on the hertz contact deformation principle," Transport in Porous Media, vol. 119, no. 3, pp. 739-754, 2017.

[23] L. Zou, L. Jing, and V. Cvetkovic, "Roughness decomposition and nonlinear fluid flow in a single rock fracture," International Journal of Rock Mechanics and Mining Sciences, vol. 75, pp. 102-118, 2015.

[24] F. Xiong, Q. Jiang, Z. Ye, and X. Zhang, "Nonlinear flow behavior through rough-walled rock fractures: the effect of contact area," Computers and Geotechnics, vol. 102, pp. 179195, 2018.

[25] A. Shahbazi, A. Saeidi, and R. Chesnaux, "A review of existing methods used to evaluate the hydraulic conductivity of a fractured rock mass," Engineering Geology, vol. 265, article 105438, 2020.

[26] X. D. Ni, Y. L. Niu, Y. Wang, and K. Yu, "Non-Darcy flow experiments of water seepage through rough-walled rock fractures," Geofluids, vol. 2018, Article ID 8541421, 12 pages, 2018.

[27] M. Javadi, K. Sharifzadeh, K. Shahriar, and Y. Mitani, "Critical Reynolds number for nonlinear flow through rough-walled fractures: the role of shear processes," Water Resources Research, vol. 50, no. 2, pp. 1789-1804, 2014.

[28] Y. F. Chen, J. Q. Zhou, S. H. Hu, R. Hu, and C. B. Zhou, "Evaluation of Forchheimer equation coefficients for non-Darcy flow in deformable rough-walled fractures," Journal of Hydrology, vol. 529, no. 3, pp. 993-1006, 2015.

[29] R. Ulusay, The ISRM Suggested Methods for Rock Characterization, Testing and Monitoring: 2007-2014, Springer International Publishing, Berlin, 2015.
[30] Y. Chen, H. Lian, W. Liang, J. Yang, V. P. Nguyen, and S. P. A. Bordas, "The influence of fracture geometry variation on nonDarcy flow in fractures under confining stresses," International Journal of Rock Mechanics and Mining Sciences, vol. 113, pp. 59-71, 2019.

[31] B. Li, Y. Liang, L. Zhang, and Q. Zou, "Experimental investigation on compaction characteristics and permeability evolution of broken coal," International Journal of Rock Mechanics and Mining Sciences, vol. 118, pp. 63-76, 2019. 